\title{
Comparison of Heat Flux Observation at Three Different Locations around Bandung, West Java
}

\author{
I Dewa Gede Agung Junnaedhi ${ }^{1}$, Kawtsar Muchtar ${ }^{2}$, Sandy Hardian Susanto \\ Herho $^{3}$, Prawira Yudha Kombara ${ }^{4}$, Faiz Rohman Fajary ${ }^{5}$ \\ 1,3,4, 5 Atmospheric Science Research Group, Faculty of Earth Sciences and \\ Technology, Bandung Institute of Technology \\ ${ }^{2}$ National Disaster Management Authority \\ Email: dewa108@meteo.itb.ac.id
}

\begin{abstract}
We observed heat flux profiles at three different locations around Bandung, West Java. Heat flux values were calculated using the covariance method with the vertical flow and potential air temperature fluctuation parameters. Observations have shown diurnal patterns in the three observation locations. We also compared observed heat flux data with estimate values using the Bulk Parameterization method. We found that the estimated heat flux was not able to produce values in accordance with the observation data. Boundary layer mixing scheme and wind shear factor were thought to influence heat flux poor estimation in Bandung using the Bulk Parameterization method.
\end{abstract}

\section{Introduction}

Atmospheric boundary layer is part of the atmospheric layer that gets direct influence from activities on the earth's surface [4]. Therefore, the interaction between the layers of the atmosphere and the earth's surface is one of the important things in the scope of scientific meteorology, hydrology, and climatology. Changes in physical parameters of the earth's surface also change the transfer of surface heat and moisture which consequently will affect the structure of the atmospheric boundary layer. An important parameter that most influences changes in the structure of the atmospheric boundary layer are the phenomenon of air mass exchange, which is represented in the energy equilibrium equation, and turbulence parameters [4]. Therefore the phenomenon of energy transfer represented through surface flux parameters is one of the important things in the study of atmospheric boundary layers.

Surface observation data from observation stations, such as wind; air temperature; etc., used as initial input in parameterization for flux calculations using various numerical weather prediction (NWP) models. There are various types of parameterization of heat fluxes used by NWP, one of which is Bulk Parameterization. This parameterization method has been widely used in various types of NWP and is usually combined with other parameters, such as the Penman-Monteith approach and the multi-source approach [2]. Although many NWP has switched to better parameterization methods, Bulk Parameterization is the simplest and easiest method to implement [5].

Previously, heat flux observations on Bawean Island were conducted using ultrasonic anemometers and AWS [5]. The results of these observations were then compared with the heat flux observations in 
Cabauw, Netherlands [3], and estimated using Bulk Parameterization. The results of this study indicate that there is a considerable difference between the results of heat flux observations on Bawean Island and in Cabauw, in other words, the Bulk Parameterization method has not been able to represent the conditions of heat fluxes in the tropics. But there is a major shortage in the study. These disadvantages include the surface air temperature data that is approached with soil temperature data, besides that the soil temperature data is taken from geographically distant locations, namely in Ujung Genteng, West Java, while observations of ultrasonic anemometers are conducted in Bawean Island, East Java.

Because of the lack of availability of data on heat flux observations used as the main reference, studies that study the heat flux characteristics in tropical regions are still very few. Therefore, it is necessary to study heat flux in the tropics and their response to differences in surface characteristics in each observation area. This study aims to find out and analyze heat fluxes at three different points in Bandung, West Java. This research was conducted on June 16, 2016, until July 21, 2016. In addition, we also estimate heat fluxes using Bulk Parameterization, the results of which are then compared with the heat flux observed data.

\section{Data and Methods}

Data used in this study are weather observation data from three different locations in Bandung. The first point located in the Dago area, precisely in the DDK regency field with coordinates $6^{\circ} 52$ ' 17.3 "S, 107 ${ }^{\circ} 37^{\prime}$ 8.9" E and an altitude of 837 m.a.s.l. (Figure 1). This location considered as a representation of the urban area of Bandung with dense settlements and little vegetation (Figure 2a). The second location is at Sulaiman Air Force Base (AFB) with coordinates 6 ${ }^{\circ} 58^{\prime} 53.1$ "S, 107 34' $25.49^{\circ}$ E and an altitude of 688 m.a.s.l (Figure 1). The second location was chosen because of flat and wide surface characteristics, with a homogeneous surface cover in the form of grass (Figure $\mathbf{2 b}$ ). The third location is in Manoko garden with coordinates $6^{\circ} 48^{\prime} 25.02$ "S, 107 36 $46.62^{\prime \prime} \mathrm{E}$ and height of 1312 m.a.s.l. (Figure 1). This location was chosen because of the hill characteristics that represent the morphology of the North Bandung region (Figure 2c).

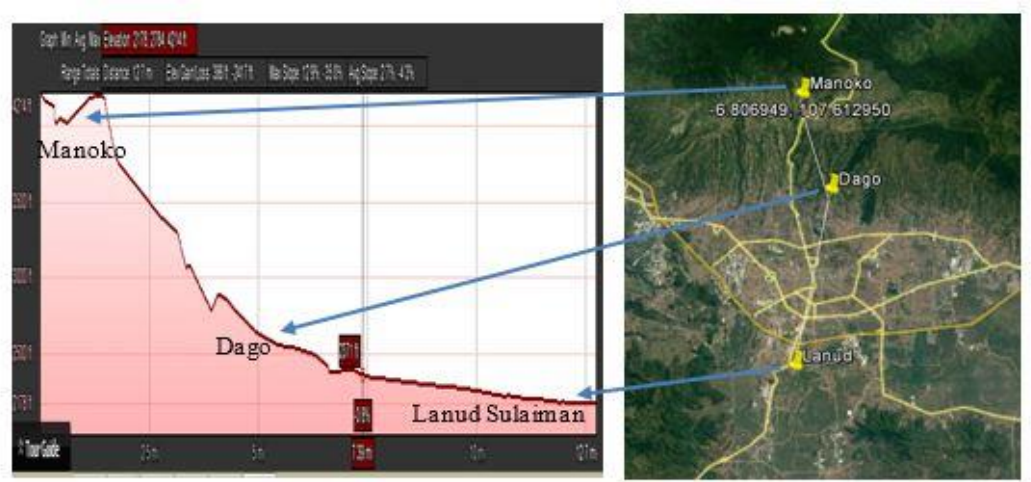

Figure 1. Coordinate and altitude of observation locations 


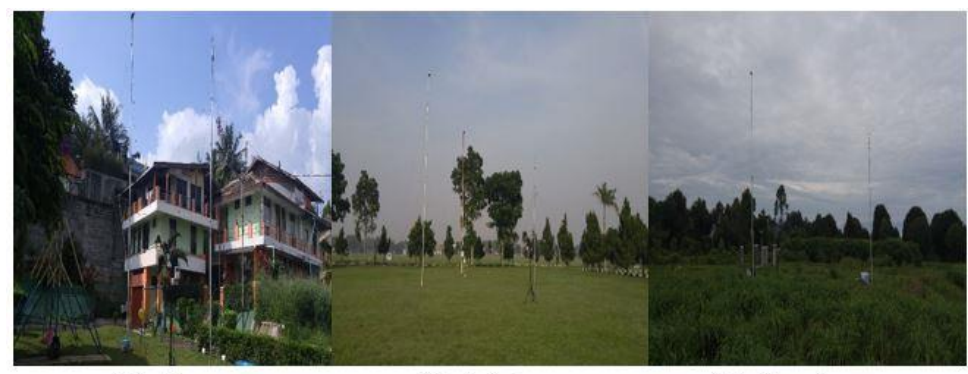

(a) Dago

(c) Sulaiman

(b) Manoko

Figure 2. The appearance of the observation locations.

There are three types of instruments used in the observation, namely Young Model 81000 Ultrasonic Anemometer, Davis Vantage Vue Automatic Weather Station (AWS), and Davis Vantage Pro Automatic Weather Station (AWS). Data obtained from the results of ultrasonic anemometer measurements are vertical wind velocity data $(w)$ and virtual air temperature $(T v) . T v$ can then be converted into a virtual air temperature $(\theta v)$ variable using equation (1). Through AWS measurements, we got weather parameter data every five minutes. The weather parameters used in this study include air temperature $(T)$, relative humidity $(R h)$, air pressure $(P)$, and horizontal wind velocity $(u)$. After we got the temperature and pressure data, then we use equation (1) to calculate $\theta v$. The air temperature data obtained from measurements using an ultrasonic anemometer is a virtual air temperature so it needs to be calculated using equation (2) so that the potential air temperature $(\theta)$ can be changed to $\theta v$. Thus the measurement results from AWS and ultrasonic anemometer can be compared.

$$
\begin{aligned}
& \theta v=T v\left(\frac{p s}{p}\right)^{R / C_{p}} \\
& \theta v=\theta(1+0.61 q)
\end{aligned}
$$

Vantage Pro AWS located at two meters above the ground and Vantage Vue AWS placed at 10 meters above the ground. This configuration is needed because the Bulk Parameterization estimation method requires data on air temperature differences at two different heights. Installation configuration of these instruments in this study can be seen in Figure 3.

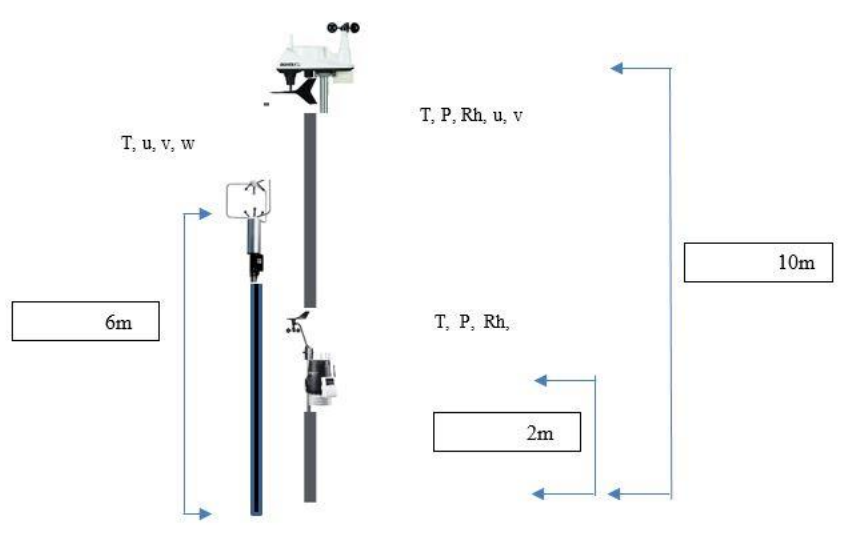

Figure 3. Instruments configuration used in observation activities. 
Calculation of sensible heat fluxes can be done by calculating vertical flow fluctuation covariance $\left(w^{\prime}\right)$ and air temperature fluctuation $\left(T^{\prime}\right)$ [3]. However, to remove the influence of altitude on air temperature, the air temperature parameter $(T)$ is replaced by potential air temperature $(\theta)$, so the fluctuation parameter used is the potential air temperature fluctuation $\left(\theta^{\prime}\right)$. The values of $w^{\prime}$ and $\theta^{\prime}$ can be calculated using equations (3) and (4).

$$
\begin{gathered}
w^{\prime}=w-\bar{w} \\
\theta^{\prime}=\theta-\bar{\theta}
\end{gathered}
$$

After obtaining the fluctuation value of the two parameters, the heat flux can be calculated using a covariance method, of course by calculating heat capacity $\left(C_{p}\right)$ and density $(\rho)$, as shown in equation $(5)$.

$$
Q h=C_{p} \rho \overline{w^{\prime}} \overline{\theta^{\prime}}
$$

To calculate the virtual potential temperature we need air pressure data. Air pressure data is obtained from the AWS average pressure measurement at two meters and $10 \mathrm{~m}$ heights from the ground, assuming a five-minute change in pressure value is insignificant because AWS measurements are carried out every five minutes. Complete calculation of heat flux can be done using equation (5). However, in this study, the parameters of heat flux used are kinematic sensible heat flux, so that the parameters of our air density are removed from the calculation. In addition, the air temperature recorded by an ultrasonic anemometer is acoustic virtual air temperature, but because the value is almost the same as the virtual air temperature parameter, we consider it the same parameter. The calculation of $\theta v$ that we did also involve variations in humidity, so our equation (5) was modified to become equation (6), which we used to calculate heat fluxes.

$$
Q h_{k} v=\overline{w^{\prime}} \bar{\theta} \overline{v^{\prime}}
$$

We were averaging the results of vertical flow fluctuation and potential air temperature fluctuation every 30 minutes. This step we use to get heat flux through the calculation with the covariance method.

To calculate the virtual potential temperature we need air pressure data. Air pressure data is obtained from the AWS average pressure measurement at two meters and $10 \mathrm{~m}$ heights from the ground, assuming a five-minute change in pressure value is insignificant because AWS measurements are carried out every five minutes. We used data from AWS observations to estimate Bulk Parameterization. We modified the Monin-Obukhov Similarity equation (7) to equation (8) because we used the virtual potential air temperature data as an input in that function.

$$
\begin{aligned}
& \overline{w^{\prime}} \overline{\theta^{\prime}}=C_{H} U(z)\left[\theta-\theta_{0}\right] \\
&{\overline{\left(w^{\prime} \theta v^{\prime}\right)_{e s t}}}=C_{H} \bar{U}(z)\left[\overline{\theta v}(z)-\theta v_{0}\right]
\end{aligned}
$$

The $\overline{\theta v}(z)$ variable is calculated using virtual potential air temperature data at 10 meters height from the ground. $\bar{U}(z)$ is the average horizontal velocity at an altitude of 10 meters from the ground. $\theta_{0}$ is the surface air temperature at two meters height from the ground. The value of $C_{H}$ used is $1.5 \times 10^{-2}$ [4].

When observations were made, it often happens to rain at different times in all observation locations, thus requiring us to group the days. Day grouping is done by classifying the day of rain observation and the day of observation is not rainy. In addition, we also classify the value of day and night heat fluxes in order to sharpen the analysis of differences in heat flux in different ground surface conditions. 


\section{Results and Discussion}

\subsection{Diurnal pattern analysis}

We process and display wind data from observations of an ultrasonic anemometer, Vantage Pro AWS, and Vantage Vue AWS in the form of wind rose graphs for general wind conditions. The wind rose graphs produced from the data of the three instruments did not show significant differences, so for the next, we will only display the wind data obtained through ultrasonic anemometer measurements (Figure 4). The wind rose graph plot shows that in the Dago observation area, the wind blows from the west, east and south directions (Figure 4a). This shows that there is no dominant wind in the Dago observation area. The maximum wind speed in Dago ranges from $2-2.5 \mathrm{~m} / \mathrm{s}$. Meanwhile the dominant wind that flow over Sulaiman came from the northeast with a tendency towards east with a maximum speed of 7 $\mathrm{m} / \mathrm{s}$ (Figure $4 \mathbf{b}$ ). Whereas over Manoko the dominant wind blew from the southeast with a maximum value range between $3-3.5 \mathrm{~m} / \mathrm{s}$ (Figure $4 \mathbf{c})$.

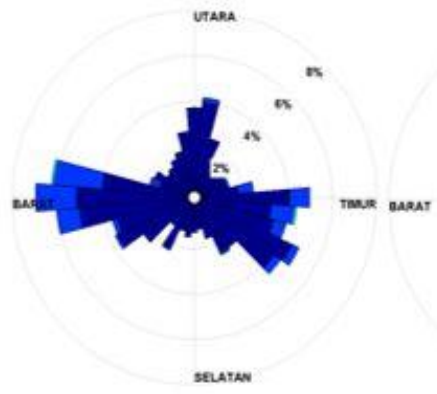

(a) Dago

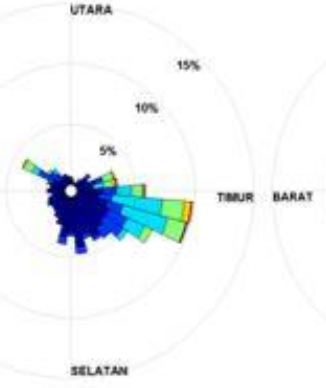

(b) Sulaiman

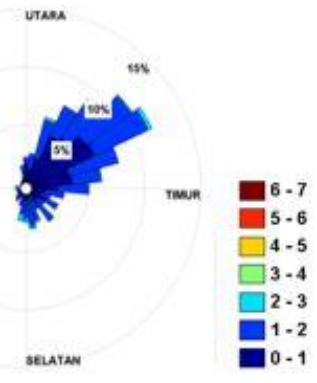

(c) Manoko

Figure 4. Wind rose graphs in (a) Dago, (b) Sulaiman, and (c) Manoko which were obtained from observations of ultrasonic anemometers.

Factors affecting wind conditions in Dago are caused by a number of buildings that surrounding the observation site. This causes the wind that blows past the Dago area to experience a deflection of direction and the intensity of the speed decreases due to surface obstacles from buildings around the observation area. In Manoko observation area, the wind flows more freely than in Dago, so there is no significant change in direction. However, the condition of the observation area in Manoko, which is a medicinal plantation with many vegetation covers and hilly contour characteristics, also influences the wind speed in the observation area. Sulaiman observation area is a very wide open space. The flowing wind does not get many obstacles, so the wind speed in this region was greater than the other two observation locations.

Figure 5 shows the values of $u^{\prime}, v^{\prime}, w^{\prime}$, and $\theta^{\prime}$ in Sulaiman. We chose to display the observations in this observation area because the characteristics of the location were in accordance with the criteria for the area of observation of heat flux, namely the location of the observation with an open state and without many obstacles, and homogeneous surface conditions. From these data, it can be seen that the fluctuations of the four variables above are influenced by diurnal patterns. During the daytime, the fluctuations of the four parameters are very high (shown in a red circle), while at night the fluctuations are relatively lower than during the daytime (indicated by a black circle). 

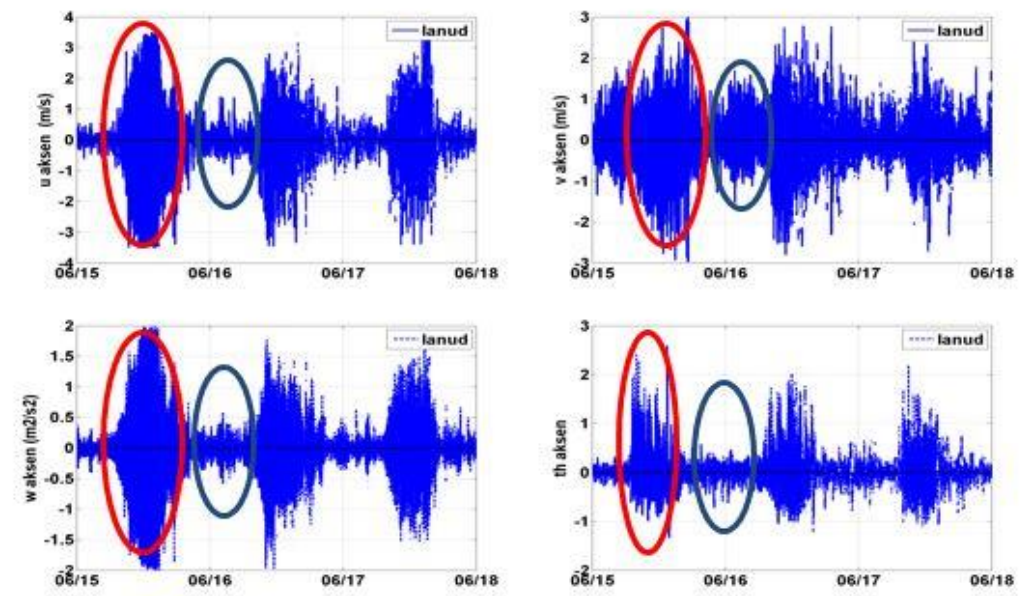

Figure 5. $\boldsymbol{u}^{\prime}, \boldsymbol{v}^{\prime}, \boldsymbol{w}^{\prime}$, and $\boldsymbol{\theta}^{\prime}$ data which were observed by the ultrasonic anemometer. The red circle shows fluctuations during the day, while the dark circles show fluctuations at night.

Based on the data shown in Figure 5, we then make a histogram to see the data distribution patterns. Only the vertical flow turbulence and $\theta^{\prime}$ data that we display are in the form of a histogram because it is through these two data that we calculate the heat flux directly with the covariance method. Figure 6 shows the distribution of occurrence frequencies from $w^{\prime}, \theta^{\prime}$, and $w^{\prime} \theta^{\prime}$ data in the three observation locations. The frequency of $w^{\prime}$ and $\theta^{\prime}$ values in Dago tends to be more negative. The same thing happened in Sulaiman and Manoko. Next, we multiply $w^{\prime}$ and $\theta^{\prime}$ variables, so we get the $w^{\prime} \theta^{\prime}$ values. The frequency of $w^{\prime} \theta^{\prime}$ values in Dago and Manoko tends to be more positive, while a number of frequencies of the $w^{\prime} \theta^{\prime}$ values in Sulaiman tends to be balanced. Based on the previously calculated $w^{\prime} \theta^{\prime}$ values, we then calculate the $w^{\prime} \theta^{\prime}$ covariance values by averaging the $w^{\prime} \theta^{\prime}$ values for every 30 minutes. These $w^{\prime} \theta^{\prime}$ covariance values are what we use as a representation of the incidence of heat flux.

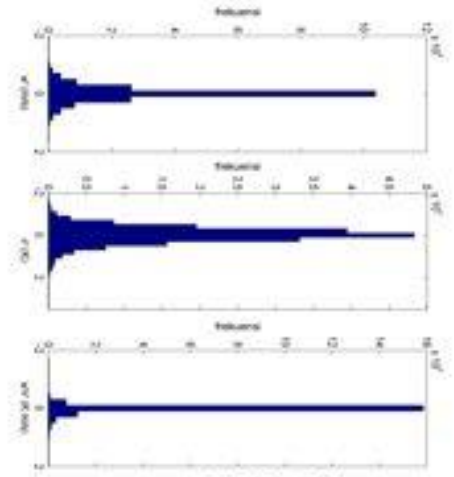

(c) Manoko

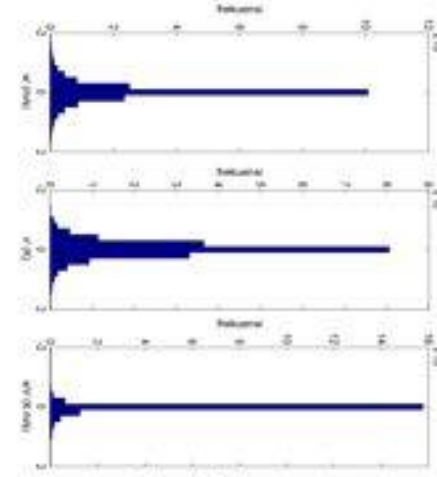

(a) Sulaiman

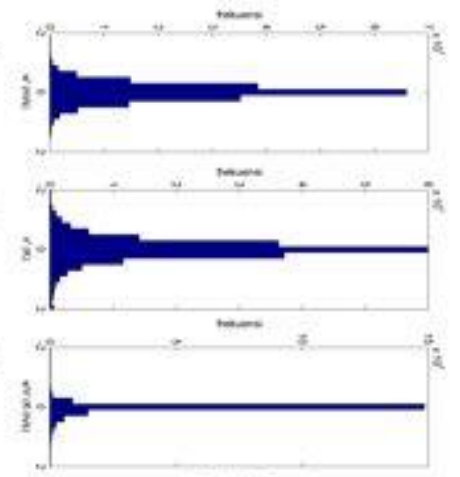

(b) Dago

Figure 6. $\boldsymbol{w}^{\prime}, \boldsymbol{\theta}^{\prime}$, and $\boldsymbol{w}^{\prime} \boldsymbol{\theta}^{\prime}$ histograms.

Figure 7 shows the comparison of the values of observations of the heat flux we performed with the results of observations of the heat flux produced by [1] study. The values range of heat flux in Bandung ranges from -0.025 to $0.15 \mathrm{~K} . \mathrm{m} . \mathrm{s}^{-1}$, while the range of values for observing the heat flux that we make 
as reference [1] varies between -0.02 to $0.2 \mathrm{~K} \cdot \mathrm{m} . \mathrm{s}^{-1}$. The diurnal pattern shown by the research that we refer to [1] shows similarities with the diurnal pattern observed by heat flux in Bandung. So it can be concluded that the calculation of the heat flux that we are working on is in accordance with the theory that we referred.

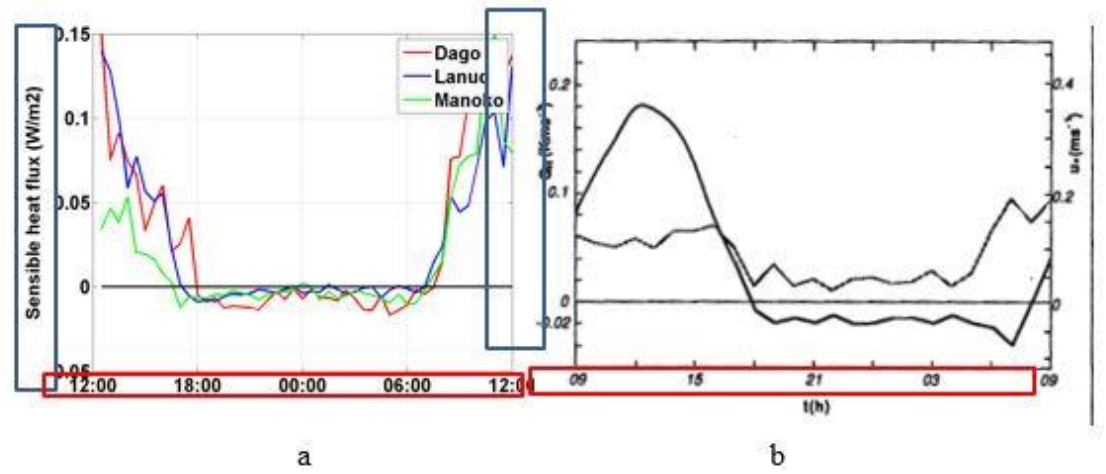

Figure 7. Comparison of heat flux (a) results of observations in Bandung and (b) results of research used as references(modification from [1]).

The results of the calculation of the heat flux that we have done shown diurnal patterns (Figure 8). At 6:00 a.m., the heat flux increases until at midday, the heat flux reaches its peak, because at that time there is a convective mixed layer formation [4]. After reaching its peak point, the value of heat flux drops slowly as the sun sinks. When the sun sets completely, the heat flux is negative.
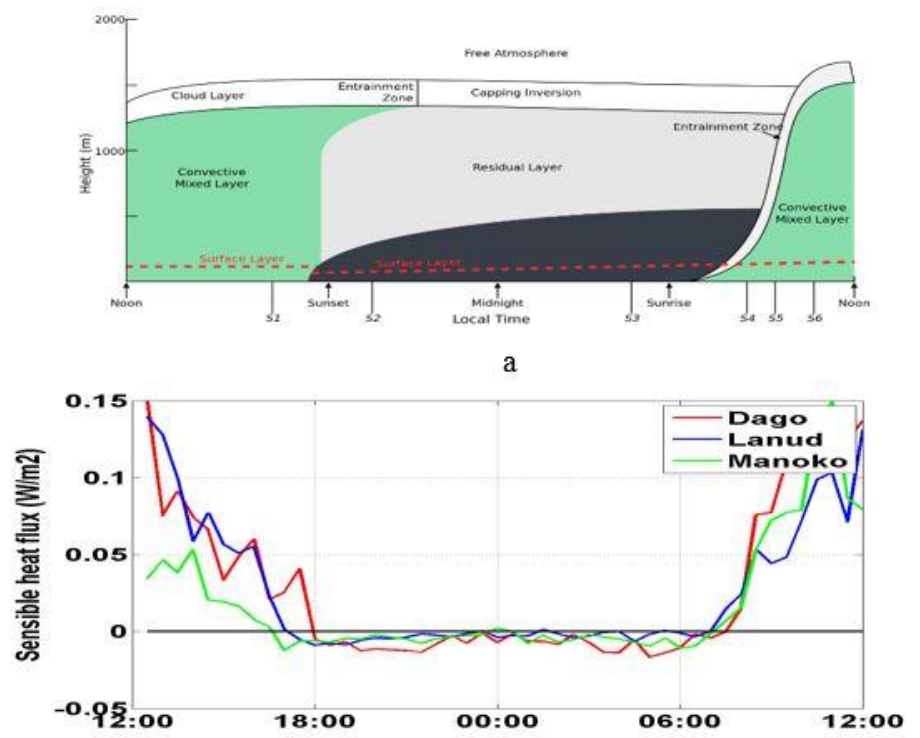

Figure 8. Projection of heat flux against the evolution of the atmospheric boundary layer. (a) Schematic evolution of atmospheric boundary layers (modification from [4]) and (b) Plotted results of observed values of heat fluxes.

\subsection{Comparison of the heat flux values in the three observation locations.}

\subsubsection{Comparison of heat flux values during the day}


Figure 9 shows the results of the measurement of heat flux on a sunny day in the three observation locations. It appears that the heat flux in Dago (which is marked by a red line) has the fastest increase in value compared to the other two observation locations. Heat fluxes at Manoko (green line) and Sulaiman (blue line) reach their peak, each of them is 0.144 and $0.1571 \mathrm{~K} . \mathrm{m} . \mathrm{s}^{-1}$, faster than Dago. The heat flux in Manoko and Sulaiman experienced a very drastic decline after reaching its peak, but again experienced an increase at 3:00 p.m. By 6:00 p.m., finally, the value of the heat flux in Manoko and Sulaiman changed to negative. The heat flux in Dago reaches its peak at 12:00 p.m. with a value of $0.189 \mathrm{~K} \cdot \mathrm{m} . \mathrm{s}^{-1}$.

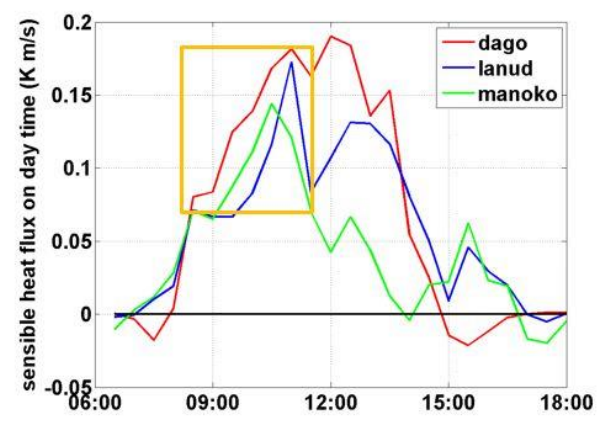

Figure 9. Heat fluxes observed during sunny days. The yellow box shows a significant increase in the heat flux values towards midday.

The observation of the heat flux at the three observation locations when rain is shown in the blue box in Figure 10. Rain that occurs when observations are carried out is suspected to be convective precipitation because it has a mild intensity and occurs during the afternoon. When it rains, the heat fluxes at Dago and Sulaiman experience a significant increase (indicated by a yellow circle). The opposite is true in Manoko when it rains at 3:00 p.m., the value of the heat flux which previously experienced an increase, suddenly drops to a negative value (indicated by a black circle).

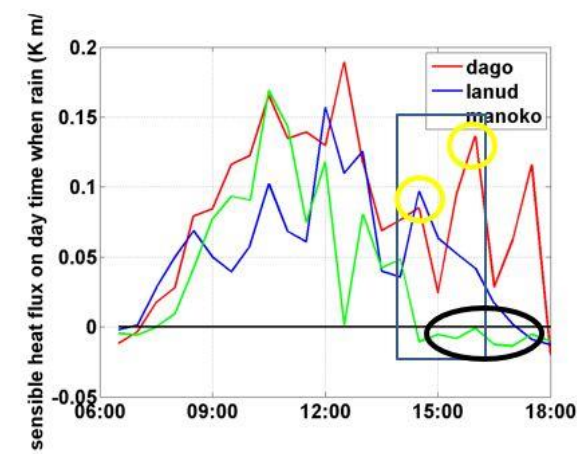

Figure 10. Heat flux values during the day when it rains. The blue box shows the time when rain occurs. The yellow circle shows an increase in heat flux values in Dago and Sulaiman. The black circle shows the negative heat flux values in Manoko. 


\subsubsection{Comparison of heat flux values during the night}

Based on observational data on the two observation locations, it can be concluded that heat flux during the clear night is more inclined to have a negative value (Figure 11). The heat flux in Sulaiman has a lower value compared to Dago at 6:00 p.m. until 9:00 p.m. At 10:00 p.m. there was a fluctuation in the value of heat flux in both observation locations. At 12:00 a.m. the heat flux in Dago experienced a very significant decline, this condition continued until it reached a positive value at 6:00 a.m. The lowest value of heat flux during the clear night in Dago is $-0.023 \mathrm{~K} . \mathrm{m} . \mathrm{s}^{-1}$, while the lowest value in Sulaiman is $-0.0117 \mathrm{~K} \cdot \mathrm{m} . \mathrm{s}^{-1}$.

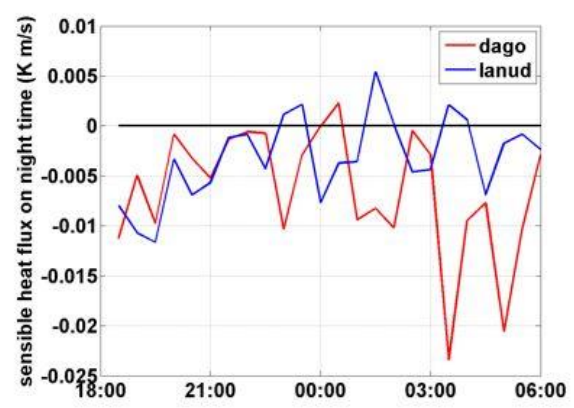

Figure 11. Heat flux values during the clear night.

Figure 12 shows the condition of heat flux at both observation locations when there is rain at night. The rain that occurs at the beginning of the night is thought to still be convective precipitation. When compared to the heat flux when the night is clear, the rain phenomenon does not significantly affect the condition of the heat flux in Dago. However, after the rain, there was a significant decrease in heat flux at 9:00 p.m. in Dago (indicated by a yellow circle). Then it can be concluded that the rain phenomenon does not directly affect the heat flux at night.

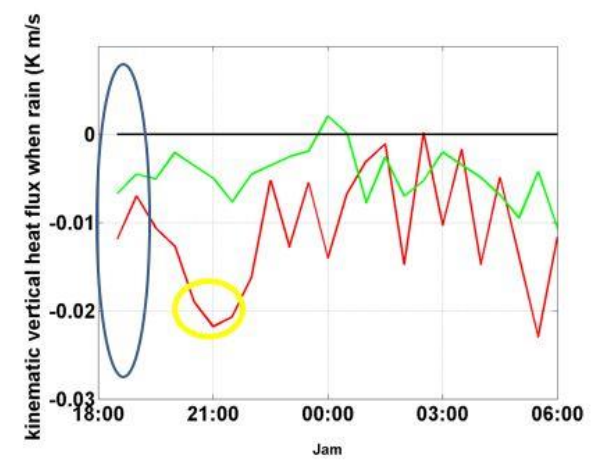

Figure 12. Heat flux values during the rainy night.

\subsection{Comparison of heat flux observation and estimation results}

\subsubsection{Comparison of heat flux observation and estimation values during the day}

Observed heat flux values are shown by the red line and the estimation results are shown by the green line in Figure 13. It can be seen in Figure 13a, that the estimation results in Dago are in line with the 
observations, but tend to take place in different time frames. At 9:00 a.m. to 1:00 p.m. the estimated heat flux results tend to stagnate at $0.1 \mathrm{~K} . \mathrm{m} . \mathrm{s}^{-1}$. Observation results showed that the heat flux in Dago reached its peak at 12:00 p.m., while based on the results of the peak estimation occurred at 2:00 p.m. These shows the time lag between the results of the observation and the estimation results until the heat flux reaches its peak. After reaching the peak point, both heat flux values decrease rapidly. Comparison of the two heat flux values in Sulaiman (Figure 13b) shows a different pattern when compared to the pattern in Dago. The heat flux from the estimation results is very slow to increase its value when compared to the observational flux. The estimated heat flux is still negative until 2:00 p.m., then it experiences a very rapid increase until it reaches its peak, and it returns down very quickly. Comparison of heat flux estimation and observation results in Manoko (Figure 13c) produced a better pattern compared to the pattern in Sulaiman. The heat flux estimation results in Manoko show a pattern that is in line with the observations. The estimated heat flux tends to fluctuate around the value of 0.5 K.m.s s $^{-1}$ until 1:30 p.m., while the observations show a continuous increase until it reaches its peak at 11:00 a.m. The estimated heat flux reaches its peak at 3:00 p.m.

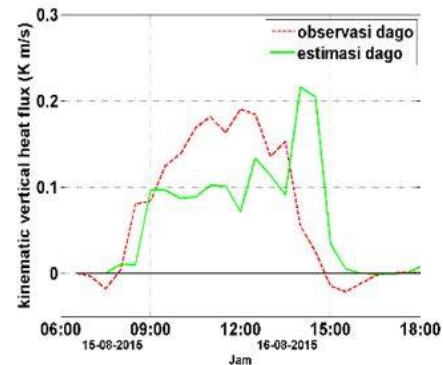

(a) Dago

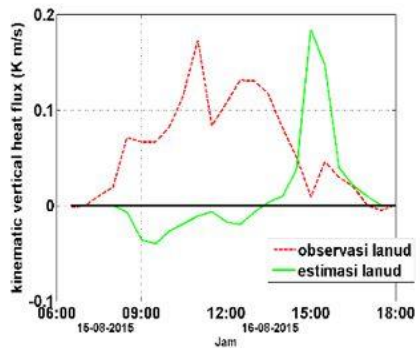

(b) Sulaiman

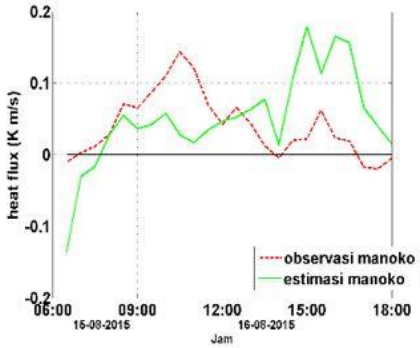

(c) Manoko

Figure 13. Comparison of the daytime observed (red line) and estimated (green line) heat flux values in (a) Dago, (b) Sulaiman, and (c) Manoko.

Compatibility of the comparison results in three observation locations is thought to be influenced by the heat flux formation mechanism. The observation location that has a buoyancy formed mechanism as in Dago generally has a greater alignment between the estimation results and the results of its observations. Wind shear factors also affect the accuracy of the heat flux estimation [3]. Wind shear is the wind velocity difference at two and 10 meters above the ground at each observation location. It can be seen in Figure 14, that the wind shear in Sulaiman is very high with a maximum value at noon reaching $2.46 \mathrm{~m} \cdot \mathrm{s}^{-1}$, while the wind shear value in Dago is much smaller. So it can be concluded that wind shear is inversely proportional to the estimation results accuracy. 


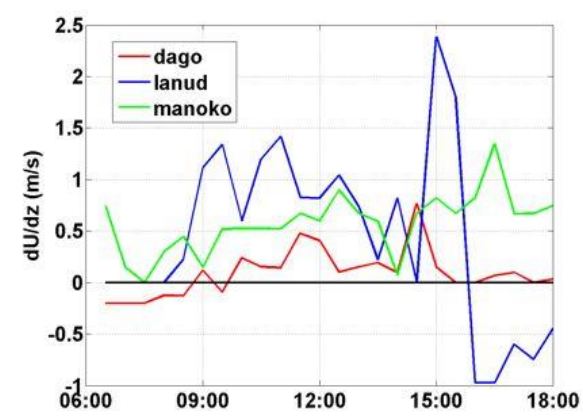

Figure 14. Wind shear charts in three observation locations.

\subsubsection{Comparison of heat flux estimation and observation values during the night}

Figure 15 shows the heat flux plots in the three observation locations at night. Observed heat flux values are shown by the red line and the estimation results are shown by the green line. There are differences in the pattern of heat flux results from estimations and observations in the Dago region. The estimated heat flux tends to have a value of $0 \mathrm{~K} . \mathrm{m} . \mathrm{s}^{-1}$, only at $02: 30$ and 05.30 there is a slight change in values to -0.01 and $0.012 \mathrm{~K} . \mathrm{m} . \mathrm{s}^{-1}$, throughout the observation period. This is different from the results of observations that show negative values throughout the observation period. At Sulaiman, the heat flux from the estimation is positive from 6:00 to 9:00 p.m., while the observation data shows the opposite. After 9:00 p.m., the estimated heat flux shows a value of $0 \mathrm{~K} . \mathrm{m} . \mathrm{s}^{-1}$, but the observation data shows a negative value. The estimation results of heat flux in Manoko showed a significant difference compared to the observation data. This large difference is seen in terms of its magnitude, the value of the observed heat flux ranges in the range of 0 to $-0.005 \mathrm{~K} . \mathrm{m} . \mathrm{s}^{-1}$, while the estimated value can even reach -0.19 K.m.s. ${ }^{-1}$.

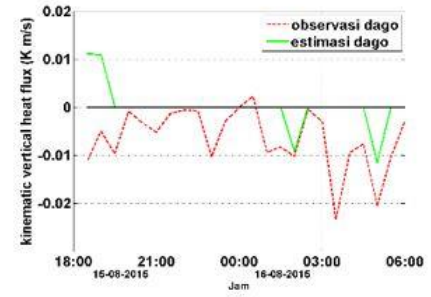

(a) Dago

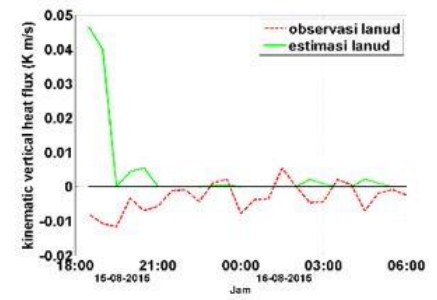

(b) Lanud

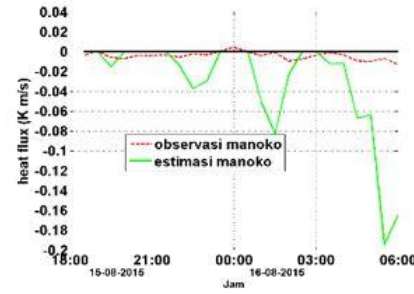

(c) Manoko

Figure 15. Comparison of the night time observed (red line) and estimated (green line) heat flux values in (a) Dago, (b) Sulaiman, and (c) Manoko.

Based on our study, it seems clear that there is an inability of estimation results to approach observation results at night. The positive heat flux at the beginning of the night in Dago and Sulaiman occurs because of the effect of the time lag from heat flux during the day. As mentioned earlier, the ability of estimation results to approach the observation pattern is influenced by the well-mixed mechanism. At night, there is no buoyant production in the process of heat flux formation, so the comparison between the observation results and the estimation results is much different. 


\section{Conclusion}

Based on the study we have done, it can be concluded that the heat flux in Bandung shows the highest value during the daytime and the lowest value at night time. The rate of increase in heat flux during the day is very fast. Manoko is the location with the highest peak heat flux and has a very fast rate of decline compared to the other two observation sites. Heat flux in Sulaiman has quite unique characteristics because the rate of increase and decrease is the slowest compared to the other two observation sites. The estimated heat flux using the Bulk Parameterization method is considered to be able to approach the observation pattern in unstable atmospheric conditions during the day and when the wind shear at the observation location is not too high.

\section{References}

[1] Andre J C De Moor G Lacarrére P Therry G Du Vachat R 1978 J. Atmospheric Sci. 351861 1883.

[2] Mahrt L and Vickers D 2003 Extended Abstract $83^{\text {rd }}$ AMS Annual Meeting. https://ams.confex.com/ams/pdfpapers/125497.pdf

[3] Schotanus P Nieuwstadt F T M De Bruin H A R 1983 Bound.-Layer Meteorol. 2681 - 93.

[4] Stull 1988 An introduction to boundary layer meteorology (Dordrecht: Kluwer Academic Publishers).

[5] Sutisna MF 2014 B.S. thesis Insitut Teknologi Bandung (ITB). 